\title{
Blurring Gender Boundaries - Masculine Confessional in Celebrity Auto/biographies
}

\author{
HANNA KYLLÖNEN, University of Sussex
}

\begin{abstract}
This paper examines the representation of masculinity within the feminine genre of auto/biography through an analysis of biographical discourses used in the construction of star personas. Auto/biographies have the potential to reverse gender roles with male stars' confessionals often discursively constructed as feminine, blurring gender distinctions within auto/biographical writing. The compulsion to confess has traditionally been seen as a feminine preoccupation but the intensification of celebrity culture would appear to have extended this compulsion to male stars. This paper examines two authorised biographies written about pop star Robbie Williams: Robbie Williams - Somebody Someday (McCrum, 2002) and Feel: Robbie Williams (Heath, 2005) and comedian and actor Russell Brand's two autobiographies: My Booky Wook (2008) and My Booky Wook 2 - This Time It's Personal (2010).
\end{abstract}

The paper analyses how in these auto/biographical narratives male stars are represented as using masquerade and role-play, as well as descriptions of mental illness and addictions to construct masculine personas. Masculinity is asserted by representing male stars through the myth of the creative genius whose talents and artistic sensitivities make them vulnerable to mental illness. Part of the masculine persona is constructed through drug/alcohol addiction and re-asserts masculinity through descriptions of promiscuous sexual adventures. There is a tension between the feminine nature of celebrity discourse and the discursive construction of a masculine persona, which appears to blur any rigid or traditional gender boundaries in these biographical narratives, and in the process of doing so, to 'prove' the 'authenticity' of the star persona.

\section{KEYWORDS}

Auto/biography, gender, masculinity, celebrity, authenticity, performance, persona, addiction, mental illness.

\section{Introduction}

In recent years auto/biographies have become increasingly central to the construction of celebrity personas. The narratives within this genre have the potential to articulate how gender is represented and understood in current celebrity culture. As celebrity culture values confession and revelation, auto/biographies have been accused of feminising masculine celebrity personas. This paper examines representations of masculinity within the feminine genre of auto/biography by analysing the construction of celebrity personas through auto/biographical discourse. The overall emphasis is on the representations of masculinity. The paper will examine two case studies based on two authorised biographies written about pop star Robbie Williams: Robbie Williams - Somebody Someday (McCrum, 2002) and Feel: Robbie Williams (Heath, 2005), and actor and comedian Russell Brand's two autobiographies: My Booky Wook (2008) and My Booky Wook 2 - This Time It's Personal (2010). Brand and Williams have been chosen due to their status as 'achieved celebrities' as theorised by Rojek 
(2001), as well as their similar experiences in relation to addiction and mental illness. Both stars also demonstrate a level of gender performance and the construction of masks and roles aimed at marketing a specific masculine image.

Blaise (1996: 201) argues that 'autobiography is the opposite of biography. Biography is an act of literary reconstruction, a celebration of, and identification with achievement.' Blaise (1996) argues that biographies tend to take a celebratory stance towards their subjects.

Biography thus deals with achievement and, according to Blaise (1996), the overall emphasis is often positive or attempts to be objective. Autobiographies, on the other hand, 'use tactlessness, humiliation and embarrassment as constructive tools,' Blaise (1996) claims. I disagree with Blaise's judgement of the differences between the autobiography and the biography. As this paper will demonstrate, there are currently more similarities than differences between the two. Both are subjective in their approach and place emphasis on the positive aspects of the celebrity's character as well as recording their failures. Bell and Yalom (1990) suggest that the boundaries between autobiography and biography are not always as distinct as their definitions imply. The biography's objectivity can be questioned, as it is influenced by the biographer's views and opinions to a larger extent than previously thought and, as a result, closely resembles autobiographies. This is particularly true today as many celebrity autobiographies are entirely written by ghost-writers. Following Blaise (1996), it could be said that biographies focus on success whereas autobiographies centre on failure. However, my discussion will show how success and failure form a continuous narrative within both autobiographies and biographies. Celebrity autobiographies deconstruct lives in detail, including struggles and humiliations suffered. Indeed, failures often form the basis from which the successes represented in autobiographies stem. The common narrative of autobiography records the downfalls and failures through which the celebrity struggles in order the achieve success and fulfilment. However, it will become clear that the points above also apply to biographies.

Auto/biography has the potential to reverse gender roles with male stars' confessionals often discursively constructed as feminine. In this way gender roles are blurred within auto/biographical writing.

Gender, as we understand and use it, is that deep imprinting of cultural beliefs, values, and expectations on one's biological sex, forming a fundamental component in a person's sense of identity. When viewed collectively, it is a system of relations between the two groups, with males almost universally in a position of dominance (Bell and Yalom, 1990: 5).

According to Kuhn (1990) conventional biography has traditionally been a male domain. Autobiography, on the other hand, has been viewed as a female enterprise. Hence autobiographies have come to be seen as feminine texts lacking the rationality of masculine biography. As Jelinek (2003: 51) puts it, historically, 'the very idea that one's domestic and emotional life constituted an appropriate subject matter for autobiography was, at least in the English tradition, essentially a female notion.' In patriarchal culture men enjoy the privilege of conceiving of themselves as the 'universal subject': rational, self-determining, transcendent and disembodied, whereas women are seen as the exact opposite, the embodied 'Other.' This paper will take the above view, as articulated by auto/biography theorists, as a starting point for defining masculinity and femininity within auto/biographies. According to this view femininity is associated with emotions and the private sphere and masculinity with rationality and the public sphere. Even though this view is traditional and possibly outdated, it serves to 
illustrate the gender fluidity of the auto/biographical narrative. The shift of attention from bios to autos, from life to the self, evident in female autobiographies, changed the focus of auto/biographies. The private and the intimate became central and the emphasis is increasingly on psychological self-observation. The above scholars see this self-observation as feminine and therefore argue that even auto/biographies written by men are feminised texts because they use a psychological approach to the self. As Adkins and Skeggs (2004: 6) put it, gender is 'extraordinarily relational, with a chameleon-like flexibility, shifting in importance, value and effects from context to context and from field to field.'

The auto/biography originally evolved from the confession which brought the requirement to reflect on one's feelings and emotions to the forefront. The religious form of confession soon developed secular qualities.

The confessional played an important role in the historic emergence of the individual, self-conscious person equipped with subjectivity and moral standards. It was part of a new personhood, organised around the key concepts of conscience, consciousness, feeling and sentiment. It was the method by which the dual self - the one that views its interiority from an external standpoint - could be performed (Skeggs, 2004: 120).

The history of autobiography is bound up with the history of (masculine) individualism (Danahey, 1993) but more recently men appear to have lost their confidence in the wake of feminism. Some scholars such as Genz and Brabon (2009) and Cohen (1990) have called this the 'crisis of masculinity,' where male subjects are as conflicted as women. Cohen (1990) argues that men are more self-conscious and analyse their lives through a psychological approach to the self. He claims that feminism convinced women that they ought to succeed in many different ways but modern men haven't had an equivalent of the women's movement hence the variety of possible roles causes confusion and insecurity. This paper shows how male stars, Williams and Brand in particular, have come to be represented in the media as neurotic and insecure - features traditionally described as feminine, especially by psychoanalysts studying female hysteria (Genz and Brabon, 2009, Cohen 1990). In the examined auto/biographies, men make confessions about themselves, exposing their inner feelings in a similar manner that the society claims that women do. Women are often represented as more emotional than men by cultural intermediaries - this is not to say that this is true. Men were once seen as rational and objective, but the opening up of gender norms allows men who choose to do so to justify their existence through confessional means. Furthermore, as seen in the case of Williams and Brand, male stars' weaknesses and failures sometimes seem to turn into addictions and macho posturing, which might be thought of as a reassertion of their masculinity. Wanko (2003: 18) argues that in auto/biographical discourse, 'female celebrities encounter representational difficulties that do not arise for male subjects.'

In opposition to this I will argue that male stars do encounter representational difficulties arising from the feminine nature of contemporary auto/biographies. Male auto/biographies need to find a balance between the feminine requirements of the confession and the masculine requirements of constructing a saleable masculine persona. The emphasis of study will be on the representations of gender and 'authenticity' in auto/biography with the aim of revealing how modern celebrity autobiographies confuse gender boundaries, play with gender through the performative, and sometimes replay traditional narratives of gender whilst claiming to represent the 'real' person behind the celebrity image. Using the auto/biography as a tool for examining both the gender confusion and gender differences at work in celebrity 
culture, the paper will aim to show that contemporary, commodified fame consists of a play with gender roles. For Butler (1990) gender is acquired and manifests itself in, among other things, a certain corporeal style, an act, which is both intentional and performative. Both feminism and autobiography theory show that the self is a construct, and that there is no unitary subject - an idea also promoted by celebrity culture. It must be made clear that traditional understandings of gender still exist alongside the performative aspects of gender. Some historically-based differences between masculine and feminine in the representation of contemporary celebrities still exist, especially between 'talented' male stars and 'famous for being famous' female celebrities.

Anderson (2001) suggests that all auto/biographical writing has cognitive and performative aspects, between what it means and what it does. She takes Rousseau's Confessions (1953) as an example, explaining that there are two aspects to his autobiography: telling (cognitive) versus excusing (performative). Like Rousseau, many celebrities have a tendency to use the performative aspects of autobiography. Instead of telling their story, they end up excusing their behaviour. In the analysis that follows the performative aspects of celebrity autobiography will become clear. Anderson believes that performance takes over because if everything could be understood through cognition, there would be nothing left to excuse, and there would be no text, no justification, or excuse for autobiography. As Anderson (2001: 51) puts it, 'the point therefore is not what Rousseau confesses but the act of confession, the drama of the self.' Rousseau's Confessions could then perhaps be seen as the first celebrity autobiography, as it paved the way for the current, performative mode in which most celebrity auto/biographies are written. Celebrity auto/biographies adhere closely to the dominant values and trends in celebrity culture, creating a drama of the self instead of rationally explaining specific incidents. The purpose is not to gain a cognitive understanding of a celebrity's life but to revel in the drama of the performing self.

Celebrity auto/biography is a specific cultural discourse that promotes individualism through confession. Initially a masculine discourse, contemporary celebrity auto/biographies have arguably become feminised texts used by both men and women to reveal their innermost feelings and the events of their lives. This allows them to promote and represent themselves as worthy of being remembered, admired and memorialised in writing. This paper will examine how masculinity based on the Romantic notion of the genius is adopted in Brand and Williams' auto/biographies. The genius stereotype is closely related to the talent and charisma which are seen to be characteristic of certain male stars (Holmes and Redmond, 2007). The Romantic ideology of the uniqueness of the individual, especially the individual genius, was 'a determining factor in the increase of confessional discourses - the confessional has become in Western culture a crucial mode of self-examination and self-expression' (Gill, 2006: 6). Celebrity culture relies on continuous self-examination by celebrities. Selfexamination turns into a confession when it is made public. The auto/biographies will be analysed as feminine discourses through notions of masquerade, roles and performance, but also as texts in which there is a reassertion of masculinity through humour, sexuality and representations of transgressive behaviour. The paper also analyses the auto/biographies as narratives of addiction and mental illness, aimed at creating 'authenticity' and exposing the supposedly 'real' self of these stars.

\section{Masculine Masquerade and Gender Performance}

Richard Dyer (1991) shows how the ideas of the 'real' and the 'authentic' are emphasised in celebrity culture. In his essay A Star is Born and the Construction of Authenticity (1991) Dyer relates 'authenticity' with 'star quality'. According to Dyer, a star's 'authenticity' is validated 
by the impression of him or her seeming to be himself or herself, and as a result, this 'authenticity' of the star creates his or her 'star quality' and secures his or her status as a star.

It is the star's really seeming to be what he/she is supposed to be that secures his/her status, 'star quality' or charisma. 'Authenticity' is both a quality necessary to the star phenomenon to make it work, and also the quality that guarantees the 'authenticity' of the other particular values a star embodies (Dyer, 1991: 133).

Celebrity is based on manipulation, but audiences still look for 'authenticity' as a guarantor of star quality. The continuous search for the 'reality' behind the image is still central in today's celebrity culture and contemporary auto/biographies are sold on the promise of the revelation of the 'real' person. However, auto/biographical writing can never guarantee the 'authenticity' so valued by the dominant discourse within celebrity culture. The illusion of 'authenticity' is generally created by exposing the aspects of the performative that construct the celebrity's public image.

Celebrity status always implies a split between the 'I' (veridical or true self) and the 'Me' (the self as seen by others). The public presentation of self is always a staged activity, in which the human actor presents a 'front' or 'face' to others while keeping a significant portion of self in reserve (Rojek, 2001: 11).

Auto/biography is supposedly a way of negotiating between the veridical and the public self. However, this is complicated by the fact that as a commercial product an auto/biography is a part of the public image of the star. Commercial celebrity auto/biographies are selective and usually aimed at 'selling' the celebrity. Auto/biographies are also performative texts with a purpose of creating a drama of the self. As cultural and commercial objects, auto/biographies are designed to be entertaining, and thus saleable. As Kuhn (1990: 4) puts it, 'in writing lives, (self) representation entails various degrees of (self) invention.' Genz and Brabon (2009) in turn argue that public and private selves are always based on socially and culturally appropriate performances. Celebrity culture has a tendency to blur the boundaries of the socalled gender appropriate behaviours. Brand and Williams challenge the patriarchal order by rejecting the macho stereotype and rational masculinity, inviting the male gaze upon themselves, appealing to both men and women but keeping the specific nature of their sexuality a mass of contradictions by playing with gender. Both also mobilise humour and camp to reject straightforward heterosexuality in constructing their public personas.

According to poststructuralist thought, individuals only exist within discourse and performativity is a discursive construction of self- signification (Whitehead, 2002). In the wake of feminism, the traditional stereotype of a hero as young, aggressive, sexually powerful, masculine and equipped with an ability to solve problems (Cohen 1990) has become less dominant. Male stars can no longer straightforwardly rely on this hero stereotype to build their image on, and many contemporary male stars portray a sexually ambivalent image that combines the supposedly feminine emotional impulse to confess, excessive macho posturing alongside an increasingly androgynous bodily image.

In the past being unforgiving and hard was the proper posture for a proper man, $[\ldots]$ whereas now men have become self-conscious narcissists and the new man can be masculine and feminine, strong and weak, active and passive (Cohen, 1990: 1, 37). 
Traditionally, masculine auto/biographies have represented men as disembodied intellects - a concept borne out of the Enlightenment notion of the creative genius. As described in his autobiographies, Russell Brand has partly drawn on this image of the tortured, talented genius to build his whole image. He also shows an awareness of its constructed and performative nature.

The ideal of the impoverished artist really pervaded that school. And drinking neat liquor from the bottle, with my long hair and my shirt undone and my beads, [...] I fitted nicely with the idea of what a creative person should be (Brand, 2008: 164-165).

In the DNA of my pompous personal mythos is the fetishisation of the artist, the belief that art hurts to make, that it's somehow sublime and torturous. (Brand, 2010: 179).

On the other hand, modern celebrity auto/biographies represent men as fully embodied and gendered beings, caught up in the play of gender roles where masculine and feminine become increasingly intertwined and sometimes in tension. Men are no longer the heroic figures of the past but appear vulnerable and have also become sexualised objects, to some extent adopting a traditionally female subject position. Thus Robbie Williams in his biography Feel: Robbie Williams articulates a desire to find love, get married and 'live happily ever after'.

I don't know. [...] I always thought there was a fairy-tale ending to all this, and naturally it was going to be love. You know, like in the songs and in the movies. [...] The last ten years have been spent most nights looking for Mrs Williams. [...] I'd like to settle down. I'd like three kids. I wouldn't mind a pot belly, actually, and a tan (Heath, 2005: 31).

But Williams seems to disguise and distance himself from his desire for love and happiness behind humour - a tendency that reappears several times in his biographies. His biographer comments: 'Much of the serious business in Robbie Williams' life is done in the shadow of not altogether innocent humour' (Heath, 2005: 29). The idea of masculine masquerade is deeply opposed to traditional beliefs about the nature of masculinity. As Brod (1987: 13) puts it: 'The masculine self has been held to be inherently opposed to the kind of deceit and dissembling characteristic of the masquerade.' Rousseau, for example, saw any kind of performance or adoption of roles as corrupting of the masculine virtues.

Rousseau [...] warns of the corrupting influences of theatrical artifice on the pure soul of the noble savage. [...] 'Real' men embody the primitive, unadorned, self-evident, natural truths of the world, not the effete pretences of urban dandies twirling about at a masquerade ball. The masquerade was the province of the female [...] [and] only effeminate men would adopt masquerade (Brod, 1987: 13).

But stars such as Williams and Brand are precisely set up as these urban dandies. Rousseau saw urban dandies as men who dressed flamboyantly for an audience, and behaved almost as if they were actors on stage, comparing these to the 'real' men who still possessed what he saw as the 'primitive masculinity' relying on what was seen as the natural order of gender differences. Like Rousseau's urban dandies, Brand and Williams adopt roles and masks to make themselves seem larger than life and these masks have become central to the constructed image. Williams' stage persona portrays him as cocky and arrogant whereas, in 
significant tension with this stage persona, his biographies represent him as an extremely narcissistic, self-conscious and insecure man. In dialogue with the stage image, Williams defends the created stage persona as stemming from his insecurities and lack of self-belief.

It's bonkers to think that this person, feeling how I feel, is going to get up and generate 10,000 people to have a good time. [...] At that time I actually had contempt for my audience for coming to see somebody so shit. I'd be on stage and think 'What have you come to see this wanker for?' (McCrum, 2002: 20, 29).

Brand's comic stage persona offers a confident and aggressive image whereas his autobiographies present a more down-to-earth, thoughtful person but one who has an 'obsession' with fame as well as an 'addictive' personality. However, these personas are not mutually exclusive. On stage Brand performs a persona through dressing in a certain way, and his performances offer him an avenue to make jokes about sex and sexuality, the nature of masculine aggression and the exploitation of women among other things. The autobiography appears to imply that both sides of the persona are a part of his narrative journey to fame but beating his aggressive tendencies and addictions have made him a stronger person by the denouement of his second autobiography. Tseëlon (1995: 41), drawing on the work of Erving Goffman, introduces the idea of 'impression management', through which social actors have 'private realities' and 'public appearances'. 'The model of a person underlying the impression management perspective is that of a manipulator who tries to control the impression people will form of them through situationally appropriate behaviours' (Tseëlon, 1995: 41-42). Brand and Williams' two personas work in this way. The stage persona is designed to entertain, shock and behave outrageously. The private persona, as represented in the auto/biographies, appeals through a representation of vulnerability and 'authenticity'. It could be said that the two personas are masks and constructions, which, working together, gain maximum exposure in the media and sell the celebrity brand.

Judith Butler (1990) has argued that becoming gender is a process of interpreting cultural reality laden with taboos, choices and restrictions. 'The choice to assume a certain kind of body, to live and wear one's body a certain way, implies a world of already established corporeal styles' (Salih, 2006: 26), in which the natural body is increasingly suspect. Brand plays up the performative aspects of gender:

So when I arrived [at stage school], still knowing how to communicate with girls because I was all feminised and everything, but being hysterically heterosexual, it was perfect (Brand, 2005: 137).

The autobiographies suggest that his camp image was constructed in his teens as a way to hide his social awkwardness; people often mistook him for a girl due to his long hair, pretty face, chubbiness, and the late onset of puberty:

One of the consequences of this was to make me very aware of my appearance. [...] As a way of coping with this, I developed a trait that I have maintained to this day when I'm around very masculine men, which is that I go all camp (Brand, 2005: 80).

Brand has consciously constructed a certain bodily style that does not adhere to mainstream masculinity and in the process created a certain mystique around his sexuality. His gender performance oscillates between masculine and feminine traits with ease but in his autobiographies he admits that adopting both masculine and feminine traits is a conscious 
strategy on his part. For Butler gender is performative and nothing within an identity is fixed. 'The binary divide between masculinity and femininity is a social construction built on the binary divide between men and women - which is also a social construction' (Gauntlett, 2008: 147). Gauntlett (2008: 150) suggests that 'rather than being a fixed attribute in a person, gender should be seen as fluid variable which can shift and change in different contexts and at different times. [...] Gender is a performance - and nothing more.' If behaviour is all that gender is, Brand and Williams' occasional excessive display of masculinity could be seen as a performance. They act in a certain way to achieve goals and produce effects. Furthermore, Butler (1990: 6) argues:

When the constructed status of gender is theorised as radically independent of sex, gender itself becomes a free-floating artifice, with the consequence that man and masculine might just as easily signify a female body as a male one and woman and feminine a male body as easily as a female one.

I would argue that in auto/biographical writing there is evidence of this 'free-floating artifice'. Male auto/biographies can take on a feminine edge as easily as a masculine one and vice versa. Both Brand and Williams are open about their emotions, insecurities, hopes and dreams. Adopting Butler's (1990: 24) argument, because 'the substantive effect of gender is performatively produced and compelled by the regulatory practices of gender coherence,' feminine male auto/biographies have a tendency to go against the norm. Even though the celebrities themselves may have a very masculine image, the discourse of male auto/biography often plays with femininity (as female auto/biography plays with masculinity). Butler (1990) argues that gender is what you do at particular times, rather than a universal who you are. However, due to the 'heterosexual matrix' retaining its dominance, feminised male stars such as Robbie Williams and Russell Brand are often ridiculed.

To return to the narratives relating to the different sides of both Williams and Brand, they make it difficult to find the 'real' person behind the series of performances. Even as they expose intimate details of their lives, sometimes in a very shocking manner, they come across as shallow or blank. They are represented as so wrapped up in the image construction that their claims of truthfulness and representing the 'real' become suspect. Arguably the process of masquerade allows male stars and their publicity machine to construct commercially viable masculine images that can be changed. Brand did not always sport big hair, black clothes, skinny jeans and eyeliner. This is an image specifically constructed as he became more famous to distinguish him from other comedians:

[I constructed] this spindly liquorice man, this sex-crazed linguistic bolt of tricks and tics and kohl-eyed winks. Clad in black like a hangman with dagger boots and hurricane hair came my creation. An organic construction sufficiently macabre to contend with the chemical warfare of modern fame, and even though this monster bore my name he did not resemble the delicate schoolboy or battered addict that preceded him (Brand, 2010: 45).

Brand's autobiographies imply that the image he portrays is constructed for being in the public eye. 'I'd organised my entire personality around fame, not to mention my physical appearance. [...] Without fame my whole persona doesn't make sense,' Brand (2010: 129130) admits. This seems like another mask, not a revelation of the 'authentic' self as male stars must be as concerned about the commodity value of their appearance as female stars. Femininity is a public performance that depends on the validation by others (Skeggs, 1997). 
This is particularly evident in the lives of celebrities who are, in a sense, always on display. As the media constantly criticise and judge celebrity bodies, even male stars are under pressure to maintain an acceptable body image. Engaging in such discourses, Brand and Williams' auto/biographies describe a certain level of construction when it comes to bodily image that includes clothes, hairstyles and tattoos as well as maintaining a certain body type. Whannel (2002: 74) describes how 'in reaction to the muscle bound hunk, recent years have seen the re-emergence of the male waif - thin, awkward, and odd. [...] This figure, often associated with drugs, [...] marks a re-emergence of a more self-destructive hedonism.' Brand's celebrity persona seems to embody the male waif whereas Williams is seen to attempt to adhere to the muscle bound hunk stereotype but struggles with his weight.

Williams readily admits in his biographies that 'Robbie Williams, the pop star' is nothing but a construction:

I developed a front a long time ago that hid my insecurities and that front is one hundred times bigger than myself. Whatever picture I paint of who they think I am, which is somebody I put up a shield to protect myself from - cocky, cheeky, confident, arrogant - is not who I am. Rob is different from Robbie. Robbie is the one who gets on stage every night (McCrum, 2002: 71-72).

Gender, as Butler (1990:x) argues, is 'a kind of persistent impersonation that passes for the real.' Williams and Brand's autobiographies articulate Butler's thesis by showing that performance of gender destabilises distinctions between the natural and the artificial. Brand and Williams show that instead of being a natural fact, masculinity and femininity form a part of a constructed image. Male stars construct masks through the use of clothing, hairstyles and even make-up. It could be said that female stars do this to create an aura of sexuality and femininity but for male stars it is often a way of making a statement. ${ }^{1}$ It is also attentionseeking as men aren't traditionally required to pay much attention to their appearance. In the auto/biographies studied, these masks are generally associated with the acquisition of fame and the need to take on an image that protects another self. Therefore male auto/biographies reveal a rift between the 'authentic' and the 'manufactured' at the same time as they combine masculine and feminine to create specific representations. If fame requires construction, masculinity is still often associated with facts, rationality and the 'truth' (Cohen, 1990). However, Brand and Williams adopt some of the dominant characteristics of Western femininity such as the importance of appearance, the fetishisation of the body and the discipline and labour associated with body maintenance. Masquerade, roles and masks thus create discursive confusion and the need to expose what lies beneath them through confessional discourse. In their auto/biographies Williams and Brand each come across as self-deprecating, mobilising irony and joking to mask the 'pain and confusion' that their auto/biographies claim are at the heart of which is the different but similarly troubled image characterising the talented artist. The constant use of irony and self-deprecating humour comes across as somewhat 'predatory' by representing transgressive behaviours and constructed personas as 'harmless fun'. The transgressive behaviours are excused through the construction of these stars as young boys unable to help themselves. The masks in auto/biographies mark the gendered sexualities of celebrities as constructed through fakery and spectacle, a hallmark of an image-obsessed celebrity culture, in which aggression, humour and transgressive behaviour are particularly associated with the image of the male star. 
Masks and performance, according to Brod (1987), could also be described as roles. Role theory brings the theatricality of the performative to the forefront. As such, it implies that a role enacts a persona different and separate from that of the actor. For celebrities, roles are often played on stage or during a public performance. Genz and Brabon (2009: 135) argue that 'male identity has become unstable, readily contestable, increasingly transferable, open to re-appropriation and constantly in motion'. Stars such as Brand and Williams appear to use the instability of the male identity in playing different roles. Heath (2005) suggests that Williams' success is largely due to his ability to perform a certain role that is expected from the 'pop star Robbie Williams'. Williams too is reportedly aware that his image as an entertainer depends on playing a fantasy role for his fans:

Compared with Presley, Sinatra, Dean Martin, Freddie Mercury, people are really conscious of themselves these days, and they are scared to do anything that would make them look silly. That's why there are not many entertainers, big showmen. What they gave you was fantasy, [...] romanticism, [...] a place to escape. They didn't keep it real. They kept it unreal. [...] I plan to keep it unreal for as long as I can (Heath, 2005: 132).

The biography emphasises Williams' wish to construct roles based on fantasy, which, according to his biographer, is justified by his desire to escape his 'real' self. Celebrity culture promotes the adoption of roles and masks and these are used by stars to create different incarnations of their personas. The masculine mask is generally worn 'in order to achieve a normative performance-oriented phallic heterosexual male sexuality' (Brod, 1987: 17). Indeed, both Williams and Brand's masculine image is associated with sex.

I was resolutely single and suddenly women were available and I did not sip like a connoisseur, I barged through the vineyard kicking over the barrels and guzzling grapes as they grew. [...] Frenzied and famished I chewed through glass and clenched the soil (Brand, 2010: 60)

The use of metaphors in Brand's autobiography accentuates an animal like sexual appetite. Both Williams and Brand have been the subject of kiss and tells on various occasions with such tabloid stories adding to the image as heartthrob, sex symbol or Lothario. Brand's autobiography The Booky Wook 2 - This Time It's Personal (2010: 63) suggests complicity with such tales:

The kiss and tells ripened through the summer. [...] Barely did I have a kiss that didn't entail a tell. To me though it didn't seem pejorative, it merely helped the narrative which they'd concocted, in which I was complicit, that I was a wild man Lothario. [...] It suited me; it was a type of notoriety that I enjoyed. The more right-wing papers used me as an icon of moral decline.

In his autobiographies Brand is seen to acquire some 'heroic' features through his sexual escapades and although he seemed to be condemned by some tabloids, their stories didn't negatively affect his overall image.

This is the kind of conduct that the News of the World and Daily Star relish. Soon the Sunday rags oozed with tales of my misdeeds, ghosts 
of the past rose from their graves, slung on a negligée and sputtered up half-truths for lazy bucks (Brand, 2010: 60).

Negative stories can cause a celebrity's downfall but most of the scandals that Brand has been associated with are represented as integral to the construction and maintenance of his image. In Brand's autobiographies sexual encounters are never recounted in terms of their emotional resonances. In Williams' biographies sex is also detached from feelings: 'The sex feels like surgery. As though his semen is being removed by an automated procedure. It is horrible' (Heath, 2005: 388). This is contradictory, as feelings relating to childhood, fame, the paparazzi, addictions, and depression are recounted in an emotional discourse through confession. This maintains my impression that in general auto/biographies confuse any rigid boundaries of what is considered masculine (detachment from feelings) and feminine (expression of feelings).

Discourses rely on available meanings and knowledge, and in the current cultural context it is more useful to talk about masculinities and femininities instead of masculinity and femininity. As demonstrated by Williams and Brand, both stars adopt different versions of masculinity at different times, occasionally reverting to what might be regarded as feminine discourses. Both Brand and Williams are seen to refuse the traditional constraints and demands of marriage and nuclear family, not settling down, sleeping with countless women, and living their lives in a haze of alcohol and drugs. Both stars come across as refusing to take on traditional adult male responsibilities. ${ }^{2}$

Both Brand and Williams construct masks so convincing that these performances are often seen as representing the 'real' person rather than constructed images. However, when it comes to the representation of stars in general, being 'real' is a contested subject. Do we ever see the 'real' person or just constructed images? Reality itself is always a construction when it comes to stars, as they come to us mediated by the culture industries through processes of emissions and selection orchestrated by management and public relations teams.

Auto/biographies are just another avenue for representing an image. If celebrity culture relies heavily on the existence of the 'real' behind the façade so too auto/biographical discourse supports the existence of the 'real' self. The auto/biographies studied in this paper indicate that the stars are purposely 'playing a role'. However, they also stress that there is a 'real' person behind the mask: 'My art is to project myself a hundred times bigger than I am, and have people to believe me' (Heath, 2005: 151) Williams appears to confess to his biographer. However, integral to these image constructions, the other side of success has been addictions and personal failure. It is important to acknowledge that the public display of failures through auto/biographies is used to build and reinforce the celebrity status and adds to the constructed image of the star.

\section{Performing Masculinity through Confessing Addiction}

The desire for fame is based on the material, economic and psychological rewards celebrity seems to offer. Holmes and Redmond (2006) stress that celebrity status has become the most blatant manifestation of success in Western culture. However, as Holmes and Redmond remind us, in addition to stories of success, more negative discourses are integral to the cultural circulation of fame. Redmond (2006: 35) argues that 'the reporting of the suffering and damage caused by fame has become a dominant discursive formation that shapes our subjectivity and identity and sets frameworks for how power and individual success are measured.' He goes on to argue that the confessional has become a central device of celebrity culture, which anchors the celebrity to 'authenticity.' Celebrity auto/biographies show up 
stardom as a faulty enterprise that can damage or destroy those subjected to it (Redmond, 2006).

In their auto/biographies both Williams and Brand are described as having a lifelong sense of personal restlessness. The paradox of an intense dissatisfaction in the midst of outstanding artistic and commercial success defines Williams, whereas Brand's restlessness appears to stem from his desire for fame. Dissatisfaction is represented as central to understanding Williams' relationship to celebrity. In spite of fame, success, and material gains, even at the height of his success he was often represented in the media as seeming to doubt himself, and being disillusioned with his position as Britain's most successful pop star.

All this has ever made me [...] is miserable and rich. What it's done, it's fucked up my family life, and it's made it difficult for me to make friends. What fame has done: it's made me fucking miserable and loaded (Heath, 2005: 481-482).

In this narrative, drugs and alcohol are used to disguise his feelings: 'I didn't start being an addict full on. It sort of gathered speed the more miserable I got. It was always there' (Heath, 2005: 86). In comparison, Brand's autobiographies imply that he nearly squandered his chance to be successful and famous by using drugs. The narrative centres on an ambition to achieve fame, which didn't happen until he gave up drugs and alcohol. 'I was born to be famous, but it took decades for me to convey this entitlement to an indifferent world and suspicious job centres' (Brand, 2010: 3). The realisation of failure is central to the discourse of fame in My Booky Wook. Brand started using drugs as a teenager, and his first autobiography relates how, over the years, he moved from softer drugs to heroin, becoming addicted to the drug to such an extent that he lost jobs, friends and girlfriends. The autobiography offers detailed descriptions of his drug use.

I got so stoned that I went to bed and was there for three days. I didn't eat or anything - just lay there bewildered. [...] I just stared and wondered and became a drug addict. From then on, I smoked draw every day without fail or exception until the narcotic baton was passed on to heroin (Brand, 2008: 126).

The above quote details how Brand first became addicted but after his drug use escalated into heroin addiction Brand is seen to become increasingly unpredictable and the drug narrative builds up Brand's outlandish persona but also implies that all professionalism went out of the window when he discovered drugs. This is in contrast to the manner in which he is seen to pick up the pieces and finally achieve fame through becoming more professional and taking pride in his work recounted in his second autobiography. The narrative account of My Booky Wook posits Brand assuming that fame would solve his existing problems, realising that this would not be the case, precipitating his heroin use.

Once I finally got a bit of success, it became clear that my internal deficit of sadness and longing would not really be sated by the things I'd always thought would save me. The realisation made me turn to hard drugs (Brand, 2008: 241).

In the autobiographical narrative Brand wants to escape reality because fame did not deliver what it had promised. Heroin, on the other hand, seemed to do exactly what it promised. But for Brand, heroin also contributes to his downfall. The narrative recounts a low point as Brand realises that he is addicted. 
I began to get anxious. I could feel myself heating up and breaking out in sweat, and then my legs started kicking and jumping. That's the worst symptom of heroin withdrawal - I can tolerate the nausea and the sweating, but I hate it when your legs go all kicky (Brand: 2008: 255).

My stage performances had become mental breakdowns for a handful of spectators. I was steadily getting sacked from all my jobs. My girlfriend had left me. My heroin use was incessant. And the only reason I hadn't made a serious attempt to kill myself was because I just thought, 'I've not done anything yet' (Brand, 2008: 271).

By exposing the addiction, the autobiography mobilises this narratively to make Brand more 'authentic' and fallible. Even though his persona is that of an (over)confident and talented genius, the addiction exposes a vulnerable side to his persona. However, the autobiography stresses that Brand would probably no longer be alive had he not stopped using heroin.

Brand's drug use is seen to escalate from recreational to full blown addiction and the narrative carries Brand on a journey towards death. If he was to achieve success he would have to give up drugs. 'The prospect of relinquishing [drugs] was terrifying. The only reason I did so was because I was more afraid of what was going to happen to me if I didn't' (Brand, 2008: 361). As the resolution of Brand's drug narrative shows, he could only achieve success after he had been to rehab and stopped taking drugs. As such the first autobiography works as a morality tale. 'Celebrity is a social construction used by the media to govern the population' (Rojek, 2001: 37). Government is accomplished by providing morality tales and role models. According to Marshall (1997) celebrities are manifestations of the organisation of culture in terms of democracy and capitalism. Cultural values are reflected in the representations of fallen celebrities as they articulate the boundaries of acceptable behaviour. Stars are seen as the epitome of the ideology of 'authenticity.' The public/private dichotomy of 'authenticity' introduces the notion of morality into stardom. As stars act out morals and values, image maintenance becomes important. Auto/biographies can be represented as morality tales where the protagonist learns from his or her past mistakes. Brand's second autobiography articulates a new found respectability as it ends with him having found his future wife, implying a new family-man image. By the end of the autobiography, he has left behind his addictions and womanising ways and the resolution looks forward to the future:

The next night we went on our first date and she was so funny and pretty but more importantly she emits some gentle power that makes me want to be good. [...] From the first date I changed. No more women' (Brand, 2010: 309).

In fact, it is rare for a masculine auto/biography to end on a note of triumph of masculine behaviour. As they are often read mainly by women, masculine auto/biographies have adopted elements of romantic fiction. In these auto/biographies there is a narrative need to find a happy ending. Even though there may be future auto/biographies, each book needs a resolution that represents the characters as having found an often normative and temporary equilibrium. Often the endings highlight the importance of personal success, and look forward to the future. Many of Brand's escapades whilst on drugs are described through humorous anecdotes. The use of humour works to add to the constructed image but the drug stories do have an effect of creating a more serious side to Brand's persona as troubled and mentally unstable. The seriousness of his addiction is represented as something that he had to conquer in order to achieve real success. As the second autobiography shows, after giving up drugs, 
Brand managed to land a role in a Hollywood film and has since become a successful actor. Therefore, the narrative of descent also allows Brand to show his strength of character - the ability to make the decision to stop taking heroin and climb up the ladder of fame again.

In a similar way, Williams went public with his alcohol and drug problems in Somebody Someday (McCrum, 2002). Williams talks about how gruelling it is to be famous and how hard he finds life in the public eye. At the beginning of the biography he declares that he has just come off drugs and alcohol and talks openly about his addictions. What is evident in Somebody Someday is that Williams' reluctance to allow himself to enjoy his career or his life is central to the representation of his persona. His two biographies reveal how struggling to find aspects of fame that he enjoys becomes part of a yet another adopted mask. However, the implication is that this is something closer to his 'real' persona than the aggressive and cocky pop star he also portrays. Feel: Robbie Williams offers several stories of addiction and depression.

He details the downward spiral in which depression and drugs chased each other's tails in his life. 'And then you develop a hideous fucking twitch.' [...] Each time he took cocaine, it would bring on the same involuntary twitch, so that he didn't even have to tell the people around him what he'd done. [...] He would sometimes drink a bottle of Sambuca in ten minutes. [...] 'I drank 25 pints of Guinness once. That was the height of it.' He often tells these tales with a certain amount of laddish bravado, but it never takes the real emotion long to catch up (Heath, 2005: 125-126).

Williams is seen to attempt to stop using drugs and going to rehab several times before he finally succeeds. What started off as experimentation is seen to escalate into an addiction. In the auto/biographies' confessional narratives drug taking is a response to the myth of fame problems solved, happiness ensuing - collapsing. However, in relation to male celebrity culture, this kind of excessive and addictive behaviour is also taken as a sign of creative genius. ${ }^{3}$ In the case of Brand and Williams, they are almost expected by the public and the media to behave outrageously and abuse illegal and legal substances to excess. Commentary on this phenomenon particularly runs through Brand's autobiographies:

I was always being warned about my behaviour but lionised for it at the same time. They'd always be telling me that I had to pack it in, but it was also clear that this was an industry that had revered Peter O'Toole and Richard Burton, and as long as you could come up with the goods, you could get away with just about anything (Brand, 2008:195).

Drug use and alcoholism then connect Williams and Brand with the masculinity associated with the creative genius. Fame seemingly gives them the opportunity and financial means to access this world and makes substance abuse acceptable. Furthermore, in addition to addictions, Brand and Williams have suffered from 'sadness' which is how they both describe depression and mental illness. Their auto/biographies seem to imply that the celebrity world often accelerates these conditions regardless of whether the sufferer is male or female.

\section{Narratives of Mental IIIness in the Construction of a Masculine Star Persona}


The Greco-Roman association of madness with genius was revived in the European Renaissance and still persists in the narratives of male stars.

From the Renaissance onwards, and especially during the Romantic era, mental illness became increasingly bound up with greatness. Only a tortured artist, according to the Romantic theory of authorship, could produce great art (Harper, 2006: 313).

Throughout the history of fame many celebrities have suffered from some form of psychiatric disorder. Mental distress has also become a central theme in celebrity auto/biographies. Initially a feminine discourse, even male celebrities are now willing to confess mental instability, but instead of creating pity or condemnation of them, mental distress often adds to the male creative genius image.

Gender is understood to be an important ingredient in the way celebrity madness is communicated and understood, with the appropriation of the 'feminine therapeutic discourses' used to reinforce the patriarchal definition of genius as a combination of male and female qualities reserved exclusively for men. (Holmes and Redmond, 2006: 291).

Auto/biographies are mythologised accounts of individual lives. Williams and Brand's auto/biographies are narratively constructed around the concept of overcoming hardships such as drug addiction, alcoholism and mental illness. Fame seems to accentuate any form of mental illness or addiction, but as the above quote implies, the representation of this phenomenon is gendered. Contemporary celebrity discourses often emphasise the connection between mental illness and fame, as in Williams and Brand's auto/biographies.

I'm in semi-retirement mode again. I've got a bit of a bummer on about my whole career so far. I'm having a melodramatic few days... about being a big shit and fake. It makes me sad that there is so much stuff out there that doesn't represent me (Heath, 2005: 480).

This is one of many similar statements within Williams' biographies. In Brand's autobiographies, narratively, mental illness becomes a central part of his personality:

I've never had a sustained period of medication for mental illness when I've not been on other drugs as well. It's just not something that I particularly feel I need. I know that I have dramatically changing moods, and I know sometimes I feel really depressed, but I think that's just life. (Brand, 2008: 376).

Although these confessions perhaps gain sympathy, they also have the opposite effect of exaggerating their 'craziness' and making them seem self-pitying about their 'sadness'. Mental illness is represented as a part of their dramatic personas. Confession of mental illness partly renders them feminine because it could be seen as narcissistic, vain and self-indulgent - features often associated with femininity.

Williams describes his manic behaviour on stage as a persona, a front that he has created, which means that he is always very aware of being in the process of performing. Behind the scenes, however, he is often represented as depressive, unable to turn down drugs. 
A really sad time actually, because I was so fucked up. I didn't know how not to do cocaine on Tuesday at five o'clock in the afternoon. I just lost the ability to say no' (Heath, 2005: 44).

Harper (2006: 314) describes mental illness as 'a token of public greatness and private vulnerability' implying that celebrity is always vulnerable to mental illness. Both Williams and Brand have been open about mental distress because for male stars credibility and mental instability seem to be interconnected. Harper (2006) suggests that female mental illness is often described as a 'battle.' Unlike their male counterparts female depressives are seen as being in a constant 'battle' with their illness whereas for men, mental illness adds to their images as mad geniuses. Male mental illness is therefore not usually seen in tragic terms. Negra and Holmes (2008) observe that the coverage of female stars 'in crisis' contrasts forcibly with the journalistic restraint often exhibited in relation to male stars and explain that the different treatment of male and female celebrities invites questions about the extent to which dignity and privacy are increasingly gendered in the context of celebrity representation. As Bell (2008: 4) puts it:

The 'bad boy' image of hedonistic excess is in many ways acceptably masculine [but] uncontained female celebrities are, by default, somehow insane. Salacious media reporting of female crisis celebrity reinforces the unrelenting representation of female celebrities per se as pathologically narcissistic and out of control.

It is difficult to describe depression on the pages of an auto/biography. This is clear from Williams' attempt to define his illness.

People think that if you are depressed, you're depressed about something. More often than not, I'm not. I just feel...terrible. And it's not about record sales or media or family. That's stuff I can pin it on. The real root of it all is, actually, I suffer with an illness that's called depression (Heath, 2005: 17).

Both Williams and Brand have also turned mental illness to their commercial advantage by exploring their problems on the pages of auto/biographical accounts and authorised documentaries. Ironically, mental illness makes them potentially more marketable, and works to maintain the perceived image. The saleable myth surrounding mental illness reassures audiences that those who make it through adversity will be rewarded. The ideological and meritocratic function of mental illness is to represent mental distress as a rite of passage leading to personal and/or professional success. Mental illness is marketable because it renders the sufferer somehow remarkable for having survived such an ordeal and going on to achieve success regardless of the 'dark times' suffered.

According to Harper (2006: 316) mental illness has a double function in contemporary culture: 'it guarantees a star's reality as a suffering subject and contributes to the perception of his or her artistic authenticity'. Mental illness implies both ordinariness and uniqueness. For a long time Williams dealt with depression by drowning his malaise with alcohol and drugs but he admits that after he stopped drinking he felt worse than when he was drinking, a situation that made him realise he was suffering from depression (McCrum, 2002). His dislike of his own songs, disillusionment with touring and his ambivalent relationship with fans are then not merely the whims of a spoilt pop star. He is represented as a complex persona whose behaviour is affected by his eternal 'sadness'. Williams has therefore benefited from revealing his mental illness. In contemporary culture, mental illness 
supposedly reveals the 'truth' about the celebrity concerned. This potentially changes the public perception of the celebrity 'reminding ordinary people that celebrities are in fact real people in a way that does not contradict or undermine their star status' (Harper, 2006: 321).

Brand has been very successful in drawing on his mental illness and addictions as material for his comedy routines, but this has also fallen apart:

I have a self-destructive streak. A thread of divine madness that sometimes makes me really funny and wild but other times makes me a fucking liability (Brand, 2010: 165).

Brand's autobiographies see him as being drawn to overly dramatic bouts of mania on stage, but he also used this to his advantage in building up his star image.

The novelty of being good at something gave vent to the wild, reckless aspects of my character. Previously, these had come in the form of tantrums, self-harm, and smashing things, but from this point onwards, they began to evolve. I started to become aware of and lovingly nurture the archetype/cliché of the self-destructive artist (Brand, 2008: 121).

Celebrity auto/biographies offer narratives of overcoming obstacles and celebrities have become the central characters used to represent difficult issues such as mental illness and addiction. However, the admission of the dramatic tendencies in their personalities can be seen as a part of the 'decadent culture of disclosure' as described by Eakin (1999: 171) who argues that personal matters have become so central that previously hidden social issues become a part of celebrity discourses where nothing is considered 'off-limits'. Many stars' narratives rely on the decadence and excesses of fame, as these are a part of the star image and are regularly reported in the accounts found in auto/biographies.

Unlike Brand who seems to revel in his fame and whose life-long ambition has been to become famous, Williams portrays an image of a star who is extremely troubled by fame and the attention he receives. To escape the pressures of fame in Britain, where he is so popular, Williams moved to Los Angeles where he could lead a relatively normal life. His biography Somebody Someday's resolution sees him happy and settled in Los Angeles, having finally found some peace from the paparazzi and the fans.

Rob's turnaround has lasted. He's still clean, happier in LA than he's been for a long time. He likes the anonymity, being away from the constant harassment of press and fans that he gets at home. In LA he can, by and large, do the normal things that normal people do (McCrum, 2002: 288).

Previously, however, Williams experienced every success and failure possible within the music industry and celebrity culture. Fame is represented as a central part of his persona.

If I wasn't Robbie Williams right now, I'd probably be auditioning for the Big Brother household. I would. Because I wanted to bigger and better myself. I wanted that dream (McCrum, 2002: 284).

But behind fame, success and popularity lies his confessing to his problems and weaknesses, which only adds to the fame. 
Historically, heroic and mythological narratives formed the basis of stories in public domain, so it is not surprising that modern stars are also represented in these terms. As Whitehead (2002: 123) puts it, 'the exaggerated behaviours and unreal lifestyle of such men only serves to reinforce the allure of their masculine display.' Addiction and mental illness combine to create a masculine representation that combines excess, aggression and vulnerability, creating particular myth of masculinity well suited to masculine stardom. 'Individuals create their own selves and realise their own desires against a scenario partly constructed by their own artistry' (Whitehead, 2002: 102). For stars, addictions, mental illnesses and sexual indiscretions become a part of the constructed self and the narrative of success and failure. Stars such as Williams and Brand are generally given leeway by the entertainment industry to misbehave and this adds to their allure.

\section{Conclusion: Blurring Gender Boundaries}

For celebrity auto/biographies, there is often an expectation that everything about the subject will be revealed as many negative stories have already circulated in the media. ${ }^{4}$ Brand and Williams' auto/biographies represent them as 'typical' of a wide range of celebrities with emphasis in their narratives on the revelation of the 'real' person behind the image. In such auto/biographies, the complete emission of emotional and sexual life that dominated the auto/biographical writing by men in an earlier era (Anderson, 2001) has disappeared. Today, confessional auto/biographies of men and women are feminine texts because, as stated earlier, the feminine text is seen to rely on the representation of emotions and the confession of every aspect of one's life and person. Butler (1990) emphasises that gender is performatively produced and relies on the regulation of gender coherence. This is why stars such as Williams and Brand confuse gender boundaries; they go against the norm in their conscious and constructed play with gender. Williams and Brand's auto/biographies emphasise male stars confessing all and their public images are often based on masquerade and role-play, 'revealing' the narcissism, self-indulgence and insecurity of male stars. Scandal and transgressions, addiction and mental illness are all common subjects in auto/biographies, and paradoxically they make male stars seem vulnerable at the same time as they construct them as talented, creative geniuses whose artistic sensitivities make them vulnerable. Alcohol and drugs are seen as an important part of this genius persona, with substance abuse having the potential to lead either to death, madness or redemption through sobriety. The genius stereotype generally allows femininity to be accommodated within the masculine persona without disturbing the intended star image. Whilst there are certain social expectations about how a person should behave that are generally gendered, male stars are often given the licence, or even expected to, behave badly and be redeemed. Certainly Brand and Williams are constructed through a specific image of the male star as both fallible and flamboyant but the expectation of morality is replaced by the public expectation of transgressive behaviour which their images are partly based on.

Auto/biographical writing promotes the existence of the 'real' person behind the image, so it might be too radical to follow Judith Butler in her insistence that gender is a mere performance and that there is no identity behind the artificial construction of gender. Celebrity has always relied on 'authenticity,' but if there is no 'authentic' or 'real' self, on what are these assumptions based? Obviously, the 'authenticity' in auto/biographies is a discursive construction, just like gender is (Skeggs, 1997, 2004). In the feminised texts of the auto/biography, masculinity is asserted through the description of promiscuous heterosexual activities and through an emphasis on the often aggressive, 'crazy' and talented public persona. Williams attests that his construction of Robbie Williams, the pop star, is very 
different from his 'real' self. Brand claims to 'really' be slightly mad and troubled, tendencies which are intensified when he is performing.

Auto/biographies have a commercial motive and put pressure on stars to tell a saleable story. Some theorists compare autobiography to the Lacanian mirror image and describe autobiographies in terms of the false recognition that a child experiences when first looking into a mirror, termed by Lacan (1977) as the mirror stage. Anderson (2001: 66) suggests:

Read in the light of Lacan's mirror stage, autobiography reveals the impossibility of its own dream; what begins in the presumption of self-knowledge ends in the creation of a fiction that covers over the premises of its construction. The subject, through autobiography, strives towards the false symmetry of the mirror, unified self which can only ever be a fiction.

Danahey (1993: 43) also likens autobiography to the mirror stage:

In his description of the mirror stage, Lacan embodies a prototypical autobiographical narrative, as the writing subject pursues a specular image of unity and self-possession that it can never achieve. The subject is constantly thwarted in its search for a unified image of itself by its awareness of the difference between the 'I' and the image in the mirror.

As celebrity auto/biographies must negotiate between the public face and the 'real' self, they can never describe the person as a whole, unified being. As commercial objects, auto/biographies must favour the side of the person that most resembles the representations in the media, whilst at the same time offering a glimpse of the unseen, some truths previously untold, and a coherent, fluent narrative journey to fame. So, unlike Rousseau, who claimed to represent his whole life truthfully, celebrities aim to represent themselves as the mirror image, as being more unified and whole than they actually are. Arguably celebrity auto/biographies represent not the Lacanian mirror image nor the 'real' person but something in between - a partly-fictional character based on the real person. As seen in the case of Russell Brand and Robbie Williams, their auto/biographies have a tendency to create an image that corresponds to the public image but also, on occasion, work as counter-narratives to press stories. However, there are also points where the narrative suggests the search for a unified self. In a sense, the requirement for a temporal narrative automatically creates a more unified self in that only certain events are chosen for representation. Auto/biography is always connected with narrative fiction (Evans, 1999).

In male celebrity auto/biographies the traditional cultural discourse of masculinity is associated with the representation of the male star as a creative genius. This is in stark contrast with the feminised discourse of the text itself, where the narrative adopts features associated with the feminine gender and style of writing, which emphasises the emotional confessional that leaves nothing to the imagination, revealing all there is to reveal, thus claiming to represent the 'truth'. Celebrity auto/biographies follow in the footsteps of the dominant discourse on celebrity in blurring the traditional boundaries of what is considered masculine and feminine. None of the celebrity auto/biographies analysed represents a coherent, straightforward gender identity. Masculinity and femininity get mixed up, appropriated into the performance of the persona. Gender becomes just one aspect of the character created for commercial purposes. At the same time auto/biographies further blur the 
distinctions between the 'authentic' and the 'constructed' which have preoccupied celebrity theorists and auto/biography theorists alike.

\section{References}

Adkins, L. and Skeggs, B. (2004) (Eds.), Feminism After Bourdieu, Oxford. Blackwell

Anderson, L. (2001), Autobiography. The New Critical Idiom, London. Routledge

Bell, S.G. and Yalom, M. (Eds.) (1990) Revealing Lives. Autobiography, Biography and Gender, Albany. State of University Press

Bell, E. (2008) 'From bad girl to mad girl,' Genders, i.48, available at http://www.genders.org/g48/g48_bell.html [Accessed 07/01/2012]

Blaise, C. (1996) 'Your Nearest Exit May Be Behind You. Autobiography and the Postmodernist Movement' in Rhiel, M. and Suchoff, M. (eds.) The Seductions of Biography, London. Routledge, 1996, pp.201-209

Brand, R. (2008) My Booky Wook, London. Hodder\&Stoughton

Brand, R. (2010) Booky Wook 2 - This Time It's Personal, London. Harper Collins

Brod, H. (1987) The Making of Masculinities: The New Men's Studies, Boston. Allen Unwin

Butler, J. (1990) Gender Trouble. Feminism and the Subversion of Identity, London.

Routledge

Cohen, D. (1990) Being a Man, London. Routledge

Danahey, M.A. (1993) Masculine Autobiography and Autonomy in Nineteenth-Century Britain, Albany. State University of New York Press

Dyer, R. (1991) 'A Star is Born and the construction of authenticity', Gledhill, C. (Ed.), Stardom: Industry of Desire, London. Routledge, pp. 132-140

Eakin, P.J. (1999) How Lives Become Stories. Making Selves, Ithaca. Cornell University Press

Evans, M. (1999) Missing Persons. The Impossibility of Auto/biography, London. Routledge

Gauntlett, D. (2008) Media, Gender and Identity: An Introduction, $2^{\text {nd }}$ Edition, London: Routledge

Genz, S. and Brabon, B.A. (2009) Postfeminism. Cultural Texts and Theories, Edinburgh. Edinburgh University Press

Gill, J. (Ed.) (2006) Modern Confessional Writing: New Critical Essays, London. Routledge

Goffman, E. (1971) The Presentation of Self in Everyday Life, London. Penguin

Harper, S. (2006) 'Madly Famous - Narratives of Mental Illness in Celebrity Culture,' Holmes, S. and Redmond, S. (Eds.) Framing Celebrity, New Directions in Celebrity Culture, Abingdon. Routledge, 2006, pp. 311-327 
Heath, C. (2005) Robbie Williams: Feel, London. Ebury Press

Holmes, S. and Redmond, S. (Eds.) (2006) Framing Celebrity, New Directions in Celebrity Culture, Abingdon: Routledge

Jelinek, E.C. (2003) The Tradition of Women's Autobiography. From Antiquity to the Present, New York. Xlibris

Kuhn, A.K. (1990) 'The Failure of biography and the triumph of women's writing: Bettina von Arnim's Die Günrode and Christa Wolf's The Quest for Christa T,' Bell, S.G. and Yalom, M. (Eds.), Revealing Lives. Autobiography, Biography and Gender, Albany. State of University Press, pp.13-28

Lacan, J. (1977) ‘The Mirror Stage’, Écrits: A Selection, New York. Norton

Marshall, P.D. (1997) Celebrity and Power: Fame in Contemporary Culture, Minneapolis. University of Minnesota Press

McCrum, M. (2002) Robbie Williams: Somebody Someday, London. Ebury Press

NEGRA, D. and HOLMES, S. (2008) 'Introduction,' Genders, i.48, available at http://www.genders.org/g48/g48_negraholmes.html [Accessed 07/01/2012]

Redmond, S. (2006), 'Intimate fame everywhere,' Holmes, S. and Redmond, S. (Eds.), Framing Celebrity, New Directions in Celebrity Culture, Abingdon. Routledge, pp.27-43

Rojek, C. (2001) Celebrity, London. Reaktion Books

Rousseau, J. (1953) The Confessions, London. Penguin Books

Salih, S. (Ed.) with Butler, J. (2006) The Judith Butler Reader, Oxford. Blackwell

Skeggs, B. (1997) Formations of Class and Gender, London. Sage

Skeggs, B. (2004) Class, Self, Culture, London. Routledge

Tseëlon, E. (1995) The Masque of Femininity, London. Sage

Wanko, C. (2003) Roles of Authority: Thespian Biography and Celebrity in EighteenthCentury Britain, Lubbock. Texas Tech University Press

Whannel, G. (2002) Media Sports Stars: Masculinities and Moralities, London. Routledge Whitehead, S. (2002) Men and Masculinities: Key Themes and New Directions, Cambridge. Polity Press

\footnotetext{
${ }^{1}$ For example most of the 'glam rock' bands in the 80s and artists such as David Bowie and Elton John used clothing, hairstyles and make-up to make statements about their personas and to distance themselves from other stars.
} 


\footnotetext{
${ }^{2}$ However, since these books were published both stars have married. Williams now has a child and appears happily married to wife Ayda Field. Brand on the other hand is now divorced from wife Katy Perry and has seemingly returned to his womanising ways.

${ }^{3}$ Numerous male stars have been associated with genius whilst also being addicts (Richard Burton, George Michael, Michael Jackson, Kurt Cobain etc.).

${ }^{4}$ However, this depends on the celebrity in question. There are different expectations for auto/biographies of athletes or politicians for example, as these are generally focused on achievement rather than scandalous revelations.
} 